\title{
Repertorio Americano: un aporte temprano a la gestión del conocimiento
}

\author{
Pedro Montero Bustabad \\ Escuela de Bibliotecología, Documentación e Información \\ Universidad Nacional, Costa Rica
}

Resumen

Se analiza cómo la revista Repertorio Americano, con base en las actividades propias de la gestión del conocimiento definidas por Thomas Davenport, realizó una gestión del conocimiento en Latinoamérica. Ya a finales del siglo XX, la Biblioteca Electrónica Scriptorium de la Universidad Nacional es su heredera y facilita su revitalización al digitalizarla.

Palabras clave: gestión del conocimiento, redes de información, Repertorio Americano, América Latina, Biblioteca Electrónica Scriptorium

\begin{abstract}
It discusses how the journal Repertorio Americano based on the characteristics of management defined by Thomas Davenport, conducted a knowledge management in Latin America. Since the late twentieth century, the Scriptorium Electronic Library, at Universidad Nacional, is its heir and makes easy its revitalization.
\end{abstract}

Keywords: knowledge management, information networks, Repertorio Americano, Latin America, Scriptorium Electronic Library

\section{Introducción}

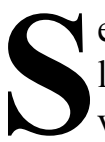
erá a finales del siglo XX cuando los científicos de la información se ven abocados a sistematizar e intentar resolver de forma teórica el concepto de gestión de la información y conocimiento. Así, emergen algunas tendencias que tratan de establecer el problema enunciado. Encontramos entonces varios planteamientos en esta dirección.
Dentro de las tendencias de pensamiento que tratan de dilucidar este problema en el siglo XX, podemos seguir la evolución que señala Domingo Valhondo, el cual asumimos como punto de partida, para examinar estos conceptos que no excluyen otros. Posteriormente, intentaremos establecer si existen matizaciones que puedan establecer nexos, que hagan viable examinar los posibles aportes de Repertorio Americano 
con esta actividad académica. De ser así, estaríamos estudiando otro muy temprano aporte cultural hispanoamericano de esta revista, áurea veta que aún no ha sido considerada por los estudios hasta ahora. A continuación se presenta un extracto de las tendencias de gestión de conocimiento planteadas por Valhondo:

"La gestión del conocimiento tiene que ver con el uso de los ordenadores y comunicadores para ayudar a la gente para recopilar y aplicar sus datos, información, conocimiento y sabiduría colectivos con el fin de tomar mejores, más rápidas y más efectivas decisiones". Gene Meieran ${ }^{1}$

Bellman enriquece esta posición: "La Gestión del Conocimiento es la transformación del conocimiento en negocios, aprendiendo mediante la transformación de información en conocimiento". Matthias Bellmann ${ }^{2}$

1 Eugene Stuart Meieran nació en Cleveland, Ohio en el 23 de diciembre de 1937. Estudió en la Purdue University el plan de estudios de metalurgia en 1959 y una especialización en el Instituto de Tecnología de Massachusetts (MIT) en Ciencia de los Materiales (Materials Science) por su interés en los cristales naturales. En 1973 inició labores en Intel como creador del "Package Development". En la actualidad es "Intel Senior Fellow" y recientemente se encuentra retirado como miembro de "Future Technology Division of Intel Research". Estuvo trabajando en aplicaciones para el intercambio de conocimientos y la colaboración con el fin de ayudar a las personas y herramientas tecnológicas para tomar mejores decisiones en forma más rápida y rentable.

2 Matthias Bellmann estudió psicología y pedagogía especializándose en educación para adultos y administración de recursos humanos. Director Ejecutivo Corporativo de Siemens AG con responsabilidades atinentes al desarrollo humano, gestión del aprendizaje y el Centro Feldafing de Liderazgo de Siemens Internacional (Alemania).
Por otro lado, Sveiby lo ve así: "Es el arte de crear valor mediante el afianzamiento de los activos intangibles. Para ello usted tiene que ser capaz de visualizar su organización como algo que no es más que conocimientos y flujos de conocimiento." Karl Eric Sveiby ${ }^{3}$

Armstrong enfatiza el lugar, el tiempo y el ambiente, con la reflexión; es así como lo dice: "Tiene que ver con elevar la conductividad de la organización para mejorar nuestra capacidad para mejorar nuestra capacidad (repetición del autor) para enlazar con el mundo exterior y nuestros clientes. Esto requiere crear el lugar, el tiempo y el ambiente apropiado para promover un trabajo reflexivo y la efectividad de nuestras interacciones." Charles Armstrong

Logan, por su lado, matiza su pensamiento con el positivismo, "el negocio" como objetivo de esta gestión de conocimiento, y lo realiza así: "Está relacionado con el uso de la información estratégica para conseguir los objetivos de negocio. La gestión del conocimiento es la actividad organizacional

3 Karl Erik Sveiby ha sido consultor y ahora profesor de gestión del conocimiento en Hanken Business School in Helsinki, Finlandia y profesor adjunto en Hong Kong. Sveiby prefiere el aprendizaje experimental y está comprometido activamente con diferentes socios elaborando herramientas para desarrollarlo. SKA, Sveiby Conocimiento Asociados, es la forma en que apoya a los que están tratando el tema de gestión de conocimiento y estas organizaciones son los mejores ejemplos: Tango TM y Interplay TM. Participa en proyectos de la simulación del negocio Buurra ${ }^{\mathrm{TM}}$ y la película documental "Treading Lightly". 
de creación del entorno social e infraestructura para que el conocimiento pueda ser accedido, compartido y creado." Robert K. Logan 4 (Valhondo, 2013, p. XXII)

Por otro lado, en un trabajo de graduación de Licenciatura de la Escuela de Bibliotecología, Documentación e Información de la Universidad Nacional, se plantea una definición en donde se lee un tinte humanista: "compartir". Este término deja ver, a nuestra interpretación, la posibilidad de gestionar el conocimiento en su sentido amplio, es decir, como función social entendida como contribución a la sociedad. Resalta, en esta dirección, el valor humanista, y por lo tanto antitético, al enfoque propio de la filosofía positivista utilitario que matiza algunas corrientes de pensamiento de esta especialidad. Seguidamente se presenta la conceptualización de la gestión de conocimiento del trabajo de graduación:

La gestión del conocimiento es actitud, decisión, conducta y compromiso, en donde se utilizan variadas herramientas, teniendo claro la filosofía de compartir el conocimiento y la información que se posee. (Miranda y Rodríguez, 2014, p. 77)

4 Robert K. Logan ha sido profesor de física en la Universidad de Toronto desde 1967. Trabajó en la física de partículas elementales, de 1965 a 1982. En 1974 comenzó una colaboración con Marshall McLuhan que duró hasta la muerte de McLuhan en 1980 después de lo cual se dedicó a la investigación en temas como por ejemplo: Teoría de la Información, Laboratorio de Innovación Estratégica, Gestión del Conocimiento, uso de computadoras en la educación, la educación científica, impacto social y la historia de los medios de comunicación, la lingüística: el origen y evolución del lenguaje.
Es importante destacar, en forma complementaria a esta perspectiva humanista, el siguiente aporte en la conceptualización de la gestión de conocimiento:

La gestión del conocimiento implica actividades o procesos como identificar, recuperar, capturar, organizar, almacenar, difundir el conocimiento para posteriormente convertirlo en un activo de la organización que beneficie y pueda generar nuevo conocimiento o actualizar el existente y se pueda compartir tanto a lo interno como a lo externo de la organización. (Valverde, 2014, p. 69)

Es, por tanto, la gestión de conocimiento un proceso que implica la realización de muchas actividades en las que la planificación, coordinación y trabajo en equipo son indispensables para lograr el éxito en los objetivos planteados.

Por tanto, en las definiciones presentadas, es posible destacar una evolución referente a la definición de la gestión de conocimiento con un énfasis más enfocado a las tecnologías de información y comunicación, con excepción de los aportes de la Escuela de Bibliotecología y de Valverde (2014). En segundo lugar, se resalta el factor humano. Se observa esta matización en Eugene S. Meieran quien apunta el uso de "computadoras" y "comunicadores". Es interesante ver el punto de partida inicial de lo que se ha enfocado anteriormente. Es decir, el aspecto técnico primero, sin descartar luego el factor humano en segundo lugar. Todo un enfoque positivista. 
Regresando al aporte integral realizado por la Universidad Nacional y por Valverde, vemos una evolución en la que se va valorando más el papel del recurso humano. Este movimiento se logra en el proceso de transformar la información como activo intangible en otro más valioso que es el conocimiento con recipiente humanista. Este se caracteriza por ser estratégico para la organización en la toma de decisiones, la innovación, la transformación y, agregaríamos, la formación integral del ser humano. Por último, se considera que la gestión del conocimiento es un conjunto de procesos que requieren especialistas de diferentes disciplinas académicas, trabajando en equipo y compartiendo el conocimiento.

Así, se establece que la dinámica de la construcción del conocimiento debe tener lugar en un balance entre el recurso humano y las tecnologías de información y comunicación. Por lo tanto, el propósito de gestionar el conocimiento y su proceso de fortalecimiento de la organización social se convierte en algo complejo.

Es relevante repetir que el recurso humano debe laborar en equipo, en forma coordinada y planificada. En esta línea, el aporte del trabajo de graduación de la Universidad Nacional es el de destacar lo prioritario del contenido humanista a la organización social. Por esta razón, se resalta como el más valioso y facilitador del proceso de aprendizaje así como del desarrollo, por lo que se accede, se usa, se comparte y se crea conocimiento en forma colectiva y en equipo.

En el pensamiento transcrito de Meieran, se menciona la sabiduría, que en sí es el fin último de la gestión del conocimiento. Este consiste en que la persona o grupo de personas adquieran nuevas habilidades $\mathrm{o}$ competencias por medio de la aplicación del conocimiento a la realidad, lo cual muestra el hecho que la generación de conocimiento implica el imperativo que se viene reseñando de factor social.

Las definiciones anteriores de gestión del conocimiento pueden fundamentar un posible marco conceptual. Este nos posibilitaría considerar las tendencias de esta especialización hasta finales del siglo XX. Intentemos recapitular estos postulados teóricos de sus autores originales citados por Valhondo (2013, p. 29-41) y considerando el aporte de la Escuela de Bibliotecología, Facultad de Filosofía y Letras de esta Universidad, y de Valverde (2014, p. 69):

a. Michael Polanyi (1891-1976): Fue el primero en plantear el conocimiento como en la actualidad es definido. Se basa en tres tesis. Primera, un descubrimiento auténtico no es explicable por un conjunto de reglas articuladas o algoritmos. Segunda, el conocimiento es público, pero también en gran medida es personal (es decir, al estar construido por seres humanos contiene un aspecto emocional, pasión). Tercera, bajo el conocimiento explícito se encuentra el más fundamental, el tácito. Todo conocimiento es tácito o está enraizado en el tácito.

b. Peter Ferdinand Drucker (1909- ): Introduce el término y concepto de "knowledge workers" en 1959 y la gran importancia de las personas en las organizaciones. Este término fue definido como los individuos que dan más 
valor a los productos y servicios de una compañía aplicando su conocimiento.

c. Peter Senge (1947- ): Su principal aporte es el concepto de "Learning organizations", organizaciones en las que los empleados desarrollan su capacidad de crear los resultados que realmente desean y en la que se propician nuevas formas de pensar, entendiendo la empresa como un proyecto común y los empleados están continuamente aprendiendo a aprender.

d. Ikujiro Nonaka (1935- ) y Hirotaka Takeuchi (1946- ): Abordaron los conceptos de conocimiento tácito y explícito y el proceso de creación del conocimiento a partir de un modelo de generación basado en la espiral del conocimiento.

e. Karl Sveiby (1946- ): Impulsó la gestión del conocimiento, con una visión práctica en lugar de teórica. Esto le permitió desarrollar herramientas tanto para su gestión como su medición. Concibe el conocimiento como el arte de crear valor a partir de los activos intangibles. En este aspecto, define las Knowledge Organizations como aquellas organizaciones totalmente adaptadas a sus clientes. Tratan a los clientes individualmente, sin forzarlos a adaptarse al producto desarrollado, sino adaptando los productos a los clientes.

f. Thomas Davenport (1954- ) junto con Laurence Prusack presentan una visión práctica de la gestión del conocimiento. Distinguen entre datos, información y conocimiento y cómo se produce el tránsito de datos a información y de información a conocimiento, mediante un mecanismo de adición de valor, que los hace evolucionar. Reconocen la importancia de las personas en el tema de la gestión del conocimiento, como contraposición al sobredimensionado papel que otros dan a la tecnología en la gestión del conocimiento en ese momento.

g. El aporte de la UNA y de Valverde a la gestión del conocimiento es como una forma planificada y estructurada. Esta como gestión social que tiene lugar en una organización o grupo de personas con un mismo propósito. Este es el de generar nuevo conocimiento, como activo intangible de carácter estratégico. Es todo un proceso, con base en el trabajo multidisciplinario.

En estos bastiones teóricos es posible destacar que la gestión del conocimiento se origina como una iniciativa orientada a mejorar tanto la racionalidad integral de una organización como su capital intelectual. Esto facilita que el conocimiento surja en forma original. Este surge inicialmente en forma tácita para posteriormente ser explícito y con posible carácter público. Bajo este precepto surge el interés de las organizaciones en valorar la función y aportes de su personal por lo que potencia el término de "knowledge workers". Bajo el concepto anterior, las organizaciones se gestionan por resultados y, a su vez, procuran el desarrollo de su recurso humano mediante el aprendizaje y éstas son conocidas como "Learning Organizations".

Otro elemento que resaltar de las tendencias modernas de la gestión de conocimiento es el término de "Knowledge Organizations". Es por medio de este término que se identifican las organizaciones que responden en forma personalizada a los intereses y necesidades propias de sus clientes sin imponerles sus productos o 
servicios. Es así como se llega a concebir el nexo que debe existir con un balance entre la valoración del aporte y función tanto del recurso humano como tecnológico. Esta dupla es indispensable para lograr la innovación y las ventajas competitivas de las organizaciones.

Según el mencionado Thomas Davenport (1998), desde su perspectiva puntualiza como actividades propias: 1) generación de nuevo conocimiento; 2 ) acceso al conocimiento procedente de fuentes externas; 3) utilización del conocimiento en la toma de decisiones; 4) uso del conocimiento en procesos, productos y servicios; 5) registro del conocimiento en documentos, bases de datos y programas informáticos; 6) crecimiento del conocimiento mediante incentivos; 7) transferencia del conocimiento disponible a la organización; 8) medición del valor de los conocimientos y del impacto de la implantación de su gestión.

Con respecto a las actividades mencionadas, es importante resaltar un elemento fundamental común entre Thomas Davenport ${ }^{5}$ y Nonaka y Taekuchi (1995). En ambas posiciones es posible resaltar que la generación del conocimiento requiere de una intervención e interacción entre personas; no existe la posibilidad de generar nuevo conocimiento en forma individual. De esta forma, por ejemplo, en Nonaka y Taekuchi ${ }^{6}$ surge la espiral del conocimiento en donde se construye uno nuevo mediante la interacción social y consiste en pasarlo de tácito a explícito. Además, esta espiral implica la aplicación del

5 Davenport, T., Prusak, L. (1998). Working knowledge. USA: Harvard Business School.

6 Nonaka, I., Taekuchi, H. (1995). The knowledge-creating company. New York, USA: Oxford University Press conocimiento a la realidad inmediata y así generar la sabiduría. Es de esta forma como esta espiral facilita la gestión de la sabiduría, que es el fin último de la gestión del conocimiento.

Para efectos de la celebración de un nuevo aniversario del Repertorio Americano, es importante plantear los posibles aportes que éste realiza a la problemática en estudio. De ser así, daría pie para considerar este enriquecimiento científico y cultural como un temprano amanecer del pensamiento hispanoamericano. Con tal propósito, nos serviremos de los ejes teóricos ya planteados por Thomas Davenport.

\section{Contexto histórico costarricense del pensamiento krausopositivista}

Como institución, Repertorio Americano germina en el suelo fecundo de la historia del pensamiento de Costa Rica, en los inicios del siglo XIX y principios del siglo $\mathrm{XX}$. En este entorno histórico, como lo apunta Montero Segura (1994, p.143) se mimetizan dos corrientes de pensamiento: el positivismo y el krausismo español.

Es importante resaltar la otra corriente de pensamiento conocida como positivismo que es caracterizada en el siguiente párrafo:

El positivismo tiene como objetivo el desarrollo científico y tecnológico con valores éticos inspirados en la positividad racional, opuestos a los ontológicos. El hombre se convierte en el medio para lograr el desarrollo del conocimiento científico y de aquí se deducen las implicaciones éticas totales. (Montero, 1994, p. 142) 
Derivada de esta interpretación, tenemos que recordar que el positivismo conllevará el nacimiento del liberalismo tanto económico como político. En Costa Rica el liberalismo económico y el político se casarán modelando el Estado liberal costarricense donde se dará, entre otros procesos históricos, el conflicto entre Estado e Iglesia juntamente con el desarrollo de la economía cafetalera. Existen otras matizaciones que no entramos a ver porque no son parte de nuestro estudio.

En este contexto histórico, inmediato casi al 15 de setiembre de 1821 , es cuando nace la primera etapa de la revista en estudio.

En el campo educativo, el liberalismo modelará un proyecto, por ejemplo el pensamiento del primer presidente de la República Dr. Castro Madriz, en el que se resalta una visión política $y$, en el marco de educación, exalta su preocupación por la educación para la mujer y la libertad de expresión. La visión liberal en este campo no está exenta de una matización pragmática.

Por otra parte, el krausismo español llega a Costa Rica con los hermanos Fernández Ferraz en el año 1871 y a partir de este momento va a constituirse como un elemento filosófico en la construcción del Estado de derecho costarricense de finales del siglo XIX y principios del XX. Matizará con el positivismo el proyecto educativo de finales del siglo decimonónico y principios del XX. El krausismo sostiene en la educación una formación integral, armónica del ser humano, cuerpo y espíritu potenciando los valores culturales del pueblo, como el de las bellas artes. El estudio de las ciencias es igualmente importante para esta filosofía. Así, el pragmatismo positivista al matizarse con el krausismo en sus contenidos espirituales, tendrá su correctivo en este campo:

Es un concepto de ciencia, en donde la idea de organismo está presente. Se resalta así mismo la presencia de Dios en ese organismo y como causa y fundamento "en todos los momentos de síntesis". Montero (1994, p. 141)

Es importante resaltar con base en lo mencionado acerca del positivismo y krausismo, que ambas corrientes en Costa Rica se imbrican entre sí, de forma similar que en España, formando el krausopositivismo:

Por otro lado, estos posibles puntos de convergencia pueden haber ayudado al proceso de imbricación de ambas corrientes. Se humaniza el positivismo, y se positiviza, en cierta manera la utopía krausista. Cristaliza así la imbricación de ambas tendencias en el denominado krausopositivismo. (Montero, 1994, p. 143)

Consideramos que en este contexto y con la filosofía mencionada, surge la publicación del Repertorio Americano como un medio de difusión y gestión de la información, tamizada con esta corriente de pensamiento.

Es así, como observamos, que el Repertorio tiene gran variedad de enfoques referentes a experiencias de vida, ámbito académico, como también de crítica social y política. Es un intento de hacer denuncias y a partir del desenmascaramiento ideológico, buscar un cambio en la sociedad costarricense 
de ese momento en busca de un desarrollo con una visión armónica. Al respecto, hay que recordar que uno de los grandes aportes de este pensamiento se da con Juan Fernández Ferraz al ser uno de los primeros en intentar estudios específicos sobre la cultura de los pueblos y asistir a congresos antropológicos sobre estos problemas concretos. ¿No es parte de la problemática de Repertorio Americano? Seguidamente, se presenta la influencia krausista en la filosofía de la educación planteada por Juan Fernández, Ferraz recogida en la obra publicada por E. Rodríguez:

Sostengo que toda enseñanza desde el principio hasta el fin, y en tanto no se llegue al límite en que las inclinaciones bien determinadas del espíritu se encarrilen en una u otra dirección hacia el cumplimiento de un fin parcial de la vida, debe ser armónica y progresiva, y ha de desarrollar al hombre todo, a semejanza de lo que nos muestra la sabia naturaleza. (Rodríguez, 1979, p. 137)

Por lo tanto, se plantea una veta para posteriores investigaciones. Emergen así varias preguntas: ¿Cuál es la corriente filosófica que modela el Repertorio Americano en este momento? ¿Continúa el krausopositivismo modelando el pensamiento del Repertorio Americano? ¿Cómo se vincula el Repertorio Americano a la filosofía educativa de la Universidad Nacional en este período?

Así, a nuestro entender, el krausopositivismo se convierte en preceptivo para el aprendizaje también, como para el desarrollo armónico de la persona, la alfabetización y la generación de conocimiento. Considerar estas raíces históricas de la publicación al resaltarlo como un medio accesible para los ciudadanos interesados en difundir el pensamiento original en diferentes formas del quehacer humano, hace viable que esta publicación se difundiera en forma impresa y por una gran variedad de países. En este sentido entendemos la gestión de información con base en el siguiente concepto:

La gestión de la información se vincula con la generación y la aplicación de estrategias, el establecimiento de políticas, así como con el desarrollo de una cultura organizacional y social dirigida al uso racional, efectivo y eficiente de la información en función de los objetivos y metas... (Aja, 2002, p. 4)

Por lo tanto, Repertorio Americano por medio de un formato de revista impresa con políticas editoriales establecidas, se trazó el objetivo de facilitar el acceso a la información actualizada de carácter social, político y cultural proveniente de diferentes países y fuentes de información. Es así como busca estimular el surgimiento de nuevos lectores y colaboradores que con información renovada, puedan colaborar publicando su pensamiento mediante un documento escrito.

Con la actividad de gestión de la información del Repertorio Americano, se erige como un recurso que colabora en la misión de alfabetizar y exponer de manera inmediata, diferentes ramas del saber, la cultura y experiencias disímiles, tanto a la sociedad costarricense como de Hispanoamérica. Entendemos la alfabetización como el concepto que a continuación presentamos: 
La alfabetización es un aprendizaje instrumental indispensable para cualquier individuo porque es una condición necesaria, sine qua non, para poder obtener nuevos aprendizajes de mayor complejidad intelectual y cultural. (Area y Guarro, 2014, p. 49)

Es posible observar, en el contexto krausopositivista y del Repertorio Americano, que el acceso a nueva información para la generación de conocimiento se facilita mediante una actitud crítica y profundo análisis fruto tanto de la investigación como de las experiencias de vida. Estas características y prácticas tanto de la alfabetización como de la gestión de información son indispensables para mantener una sociedad democrática, en donde el ciudadano tiene posibilidad de participación, como es posible observarlo:

...Una sociedad democrática requiere de una masa crítica de sujetos alfabetizados para que puedan ejercer y hacer uso de sus derechos como ciudadanos. No podrá haber democracia si existen bolsas de analfabetismo. (Area y Guarro, 2014, p. 49)

Es posible observar que el Repertorio Americano fue un medio que facilitó la propagación de esta filosofía al mismo tiempo que colaboró con la alfabetización y gestionó información en América Latina, promoviendo así los valores de una sociedad democrática como es la costarricense.

\section{Historia y características generales del Repertorio Americano}

\section{Historia del Repertorio Americano}

La revista Repertorio Americano fue fundada en el año 1919 y editada por el Benemérito de la Patria Joaquín García Monge hasta el año 1958. Es a partir de la muerte del Sr. García Monge que la Universidad Nacional, por medio del Instituto de Estudios Latinoamericanos -IDELA-, recibe los derechos de la mencionada revista y decide continuar publicándola. Esto es posible observarlo en lapágina web de $R e$ pertorio Americano elaborada por el Instituto de Estudios Latinoamericanos:

La Revista Repertorio Americano fue fundada en 1919 por el Benemérito de la Patria Don Joaquín García Monge, quien la editó hasta su muerte en 1958. Desde 1974, es publicada por la Universidad Nacional (a la cual le fueron cedidos los derechos por los herederos del Maestro García Monge), específicamente por el Instituto de Estudios Latinoamericanos que es, asimismo, depositario de la Colección Repertorio Americano, 1919-1958.

Repertorio Americano, Segunda Nueva Época, es una publicación académica, anual, inscrita en el Programa Integrado Repertorio Americano, del Instituto de Estudios Latinoamericanos, IDELA. Como revista universitaria, se encuentra formalmente constituida como proyecto de extensión, evaluado, aprobado y refrendado por las instancias académicas competentes. 
Repertorio Americano, Segunda Nueva Época, mantiene la impronta garcíamongeana de acercamiento y conocimiento de los pueblos por la cultura. Desde el Consejo Editorial se asume como una publicación con visión latinoamericanista que enfatiza los ejes estratégicos del IDELA: identidades, cultura, desarrollo y derechos humanos. (Instituto de Estudios Latinoamericanos, 2016, p. 1)

Es de requisito destacar en la línea del contexto que dio origen a la revista Repertorio Americano, la posibilidad de identificar tres momentos históricos y editoriales:

Es posible establecer tres etapas editoriales en la perspectiva histórica de la Revista Repertorio: en 1826, dirigida por don Andrés Bello, un segundo momento, que abarca de 1919 a 1958, cuando el impreso es editado y dirigido por don Joaquín García Monge quien abiertamente define que esta etapa tiene en el Repertorio de Bello un ideal y un ejemplo a seguir; y el tercer momento, cuando a partir de 1974 los derechos de publicación de la revista de Joaquín García Monge fueron cedidos a la Universidad Nacional de Costa Rica. (Soto, 2013 p. 153)

Es decir, se suma una etapa más a las mencionadas en la cita anterior por el IDELA. Determinar como primera etapa o inicial en 1826 dirigida por el Sr. Andrés Bello, -cinco años después de la fecha que generalmente se señala como la de la independencia de Costa Rica. La segunda etapa gestionada por Joaquín García Monge
(1919-1958) y la tercera etapa en 1974 momento en que la Universidad Nacional asume las responsabilidades cuando logra los derechos de publicación. Lo anterior es posible observarlo en el aporte de M. Soto

Asumiremos esta perspectiva de tres momentos editoriales del Repertorio Americano para los efectos de realizar el análisis que aspiramos brinde ejes para la reflexión posterior sobre el tema de la gestión del conocimiento.

\section{Primera etapa editorial}

La primera etapa, para efectos de ubicarnos en el contexto de Repertorio Americano, fue el comienzo de una iniciativa de difundir y compartir información que únicamente logró publicar cuatro números pero, a su vez, ser la inspiración o ejemplo para Joaquín García Monge, como es posible analizarlo en las declaraciones de Isaac Felipe Azofeifa y que son recogidas por Soto:

El Repertorio Americano es un nombre venerable en las letras de nuestro continente. Andrés Bello lo creó en Londres en 1826. Después de los primeros cuatro números ese título quedó suspendido en el aire como una bandera, como un reto. Un siglo después, el oscuro maestro de un todavía más oscuro país de Centroamérica recogió el desafío y con el nombre otra vez de Repertorio Americano lanzó un cuadernillo mensual de escasas veinte páginas. (...) Veinticinco años más tarde, Repertorio Americano (...) recorría los caminos en todas direcciones, repartiendo la voz de España y de 
América por el mundo. El último día de octubre de 1958 murió aquel singular director del Repertorio. ¿Querría don Joaquín que su obra muriese con él? Todo lo contrario... (Soto, 2013, p. 156)

\section{Segunda etapa editorial}

En la segunda época, podemos destacar que Joaquín García Monge realizó un esfuerzo de mantener una publicación por treinta y nueve años en los que existieron elementos que influyeron, tanto de carácter económico, social, político como también cultural.

Las dificultades económicas fundamentalmente se debieron a las pocas suscripciones y también al rápido abandono del pago de estas y la constante lectura de la publicación. Sin embargo, es pertinente destacar que en 1927 García Monge dio a conocer una lista de "Agencias de Repertorio Americano", con el propósito de facilitar tanto su venta como distribución y lograr su mantenimiento. Esto se enfoca así:

En 1927 aparece bien articulada una red de agencias de Repertorio Americano que crecía paulatinamente sin desmayo, en esa ocasión, el editor expresaba su deseo de establecer Agencias del Repertorio en el exterior, a razón de 8 cts. oro americano el ejemplar. Se compromete a remitir a cualquier país del mundo los que se le pidan. (Oliva, 2008, p. 36)

Con respecto al contenido vinculado al elemento cultural, en un inicio García Monge tuvo que tomar contenidos de otras publicaciones (periódicas y revistas) como por ejemplo: Nosotros, La Nación, La Nota e Ideas de Buenos Aires, El Mercurio peruano de Lima; Revista de la Facultad de Ciencias y Letras, El Fígaro y El Universal, de La Habana; El Magazine de la raza, La Reforma social de Nueva York; El Mercurio de Valparaíso y de Santiago de Chile; Revista Universitaria y Cultura de Bogotá; Patria de Asunción. Con el tiempo esta situación cambió hasta tal punto que los mismos autores debieron esperar para ver publicado su texto; Oliva nuevamente nos brinda su aporte al respecto:

Las casas editoras de América y España, incluso de Francia, vieron en la figura de García Monge y en las páginas de Repertorio Americano la mejor manera de divulgar sus colecciones, o las novedades bibliográficas. García Monge, a lo largo de los años, fue acumulando enormes cantidades de materiales, autores conocidos y desconocidos que le enviaban de muy diversas partes del mundo. (Oliva, 2008, p. 34)

Es así como Repertorio Americano llegó a consolidarse como una publicación internacional que compartía gran variedad de aportes de diversas partes del mundo con periodicidad regular y era leída por diferentes tipos de lectores de Hispanoamérica. Oliva profundiza el asunto en discusión:

Una revista como Repertorio Americano debió de ejercer una atracción inmejorable para los escritores hispanoamericanos, si se toma en consideración que se trataba de una publicación que supo mantener una 
frecuencia en su salida, cada dos semanas en promedio, lo que se considera inusual para la época. Aunado a esta regularidad, el impreso, gracias a la política de circulación desarrollada por su editor, tenía la posibilidad de ser leído por muchos posibles lectores. Es por ello que muchos escritores expresamente acotaban que sus envíos eran originales; sobre todo, durante los años veinte $\mathrm{y}$ treinta del siglo veinte. (Oliva, 2008, p. 33)

Es relevante resaltar que el aspecto de generación de contenidos para ser publicados en este medio está enraizado en el ámbito político. Ambos se interrelacionan cuando se consolidaron a su alrededor redes de intelectuales con una afinidad social, cultural y política. En el período de 1936 a 1939 tiene lugar la Guerra Civil Española. Ambos proyectos coinciden y esta publicación llega al punto de consolidarse como el medio escrito más relevante en América Latina y que brinda su apoyo a la República Española. Ambas instituciones en esta relación son descritas así por Oliva:

Por otra parte, un aspecto crucial de estas conexiones lo establece un hecho de carácter político: la Guerra Civil Española. Durante el conflicto (1936-1939) la publicación se constituye en uno de los medios de comunicación escrita más destacados en América Latina en apoyo de la república española. Difunde, de un lado, las letras españolas y americanas republicanas; de otro, la revista fue el eje o círculo concéntrico desde donde se diseminó un movimiento social y cultural iberoamericano solidario que incluyó campañas de ayuda, redes de intelectuales y sectores progresistas que se conmovieron con los agitados y traumáticos acontecimientos españoles. (Oliva, 2008, p. 34)

Repertorio Americano fue censurado por algunos gobiernos de América Latina y Centroamérica según lo analiza también Oliva:

El tema de la censura de la revista Repertorio Americano (en el medio costarricense) ni siquiera se ha insinuado. Los impresos, sean estos libros, folletos, o revistas como en el caso que nos ocupa, revisten una significación especial para la divulgación de las ideas, y la movilización social inclusive. Muchos gobiernos de América, sobre toda en la región centroamericana, vieron en esta revista un trasmisor de ideas peligrosas y desestabilizadoras. (Oliva, 2008, p. 37)

El Repertorio Americano pasa a ser identificado como un medio que difunde ideas peligrosas y desestabilizadoras. Estos gobiernos emplearon diferentes recursos para impedir su distribución; sin embargo, no impidieron que por la clandestinidad llegara a las manos de los lectores.

\section{Tercera etapa editorial}

En lo referente a la tercera etapa del Repertorio Americano, es necesario destacar que primeramente se crea la Universidad Nacional con un consejo inicial liderado por el Presbítero Benjamín Núñez. Según Soto: 
La Universidad Nacional de Costa Rica fue creada mediante la Ley 5182 del 15 de febrero de 1973 para organizarla administrativa y académicamente, a los ocho días de aprobada la Ley, el consejo de gobierno nombró una comisión ad-hoc, liderada por el Presbítero Dr. Benjamín Núñez Vargas y compuesta por los ministros de educación, Lic. Uladislao Gámez; de planificación económica, Lic. Oscar Arias Sánchez y de trabajo, Lic. Francisco Morales; además de un selecto grupo de académicos de la Universidad de Costa Rica con rango de catedráticos asociados. (Soto, 2013, p. 159)

La Universidad Nacional fue creada así con la ideología de la Universidad Necesaria latinoamericana. Promovía la participación y formación de los sectores menos favorecidos del desarrollo nacional de la década de los 70. Seguimos el pensamiento de Soto Ramírez (2013, p. 161) en el que es posible destacar que esta Universidad tendría como misión establecer directa relación entre investigación y desarrollo, participación en los planes de desarrollo, mejoría de las condiciones sociales, formar profesionales en concordancia con las exigencias de desarrollo del país y no únicamente del mercado. Se resalta que esta institución educativa pública fue erigida con una misión de cultura y de humanismo bajo el paradigma de la Universidad Necesaria. Por este motivo, es que se buscaba una cultura, no elitista ni degradada para las masas sino liberadora, dignificadora, en su más amplia acepción, de la condición humana en un contexto humanista, de compromiso, científico y el pensamiento intelectual proveniente de la Escuela Normal de Omar Dengo.

En la línea ideológica proveniente de la Escuela Nueva, el Lic. Francisco Morales Hernández logra con éxito una serie de gestiones para que el Dr. Eugenio García Carrillo cediera los derechos del Repertorio Americano editado por Joaquín García Monge a la Universidad Nacional, como parte de la iniciativa de volverlo a publicar.

La creación de la UNA es fortalecida por la decisión de publicar nuevamente $R e$ pertorio Americano. Tanto culturalmente como políticamente se vinculan en primer lugar, en su emplazamiento geográfico: la provincia de Heredia, y en segundo lugar, la creación de una institución fundamentada en una filosofía educativa humanista. Busca, entonces, las características de calidad, pluralidad y transformación lograda por el Repertorio Americano. Soto nos vuelve a iluminar sobre este asunto:

Finalmente, la importancia de la ciudad de Heredia cuna de la nueva universidad, por haber sido escenario de desarrollo de la Escuela Normal que durante siglos agitó el pensamiento, la conciencia y las culturas nacionales, que había sido dirigida por García Monge y sus discípulos, reforzaba la justificación de que Repertorio Americano volviese a ser publicado ahora por la UNA. La Revista regresaba, en cierta forma, a su origen. (Soto, 2013 p. 165)

Es por medio de Repertorio Americano que la Universidad Nacional logra 
fortalecer su carácter internacional, en su imagen de universidad latinoamericana con las características de convicción popular y transformadora, mediante el desarrollo del ser humano, acercando los pueblos por su cultura y su educación. Por estos motivos, el Repertorio Americano en esta etapa consolidó una red de colaboradores que en su comienzo se gestionó personalmente por co-editores y por contacto directo de diferentes partes del mundo, según lo menciona Soto:

La red de colaboradores durante la tercera etapa se gestó originalmente por conocimiento personal de los dos primeros co-directores y de distinguidas personalidades del mundo cultural y de las letras costarricenses, y por contacto directo fue creciendo para abarcar a los jóvenes escritores y catedráticos universitarios, así como a intelectuales de las diferentes latitudes latinoamericanas. (Soto, 2013, p. 170)

Esta red de colaboradores facilitó que esta publicación lograra asumir la función de un órgano de divulgación cultural y de promoción de nuevas ideas académicas latinoamericanas, en especial, referidas a la literatura, las artes, la educación, la pedagogía y el humanismo regionales. Así es posible conceptualizar que Repertorio Americano en su tercera etapa se constituye en un medio que exhibe la producción documental de Latinoamérica, además difunde nuevos avances de investigación y sus resultados. Da a conocer, también, trabajos de reflexión y artículos sobre la realidad latinoamericana con perspectiva latinoamericanista.
Cada etapa de publicación del Repertorio Americano tuvo un contexto que definió una evolución y sus características propias que a continuación las retomaremos para estudiarlas en relación con la gestión del conocimiento.

\section{Características del Repertorio Americano}

Es pertinente recordar que como características fundamentales, Repertorio Americano fue una publicación que creó un espacio en el que los hispanoamericanos pudieron compartir sus aportes en su realidad inmediata. Es así como se consolidó en un recurso de información que fue construido por el aporte de ciudadanos de diversas nacionalidades, edades, intereses y perspectivas en temas relevantes en aquel momento. Carvajal enriquece con su pensamiento este ángulo:

Con el Repertorio Americano, los costarricenses contaron con un punto de encuentro, un espacio para que todas las personas externaran ideas, inquietudes, denuncias y esperanzas. Por su medio García Monge logró establecer una dinámica de interacción y construcción de una comunidad ideal, supranacional, política con una base hispanoamericana que escribía y a la cual se dirigía la revista. Por eso, la revista ofrecía una amplia gama de cultura universal, en donde las relaciones entre España y América se destacaron, como se puede apreciar en las diversas reflexiones críticas de pensadores españoles y americanos que sustentan el 
pensamiento continental y que se publicaron en el Repertorio. (Carvajal, 2007, p. 148)

Estos pensamientos nos posibilitan resaltar dos características muy importantes que hicieron del Repertorio Americano una publicación distinguida y predilecta para muchas personas. Como lo hemos resaltado, es un espacio para dar a conocer información innovadora y producir nuevo conocimiento regional. Son, entonces, fruto de las investigaciones o experiencias vividas y la dinámica propia del trabajo colaborativo. Esta sinergia de trabajo involucró la sistematización de toda la información o contenidos recibidos para ser publicados en las páginas de la revista. Implicó que pudiera ser accesada fácil y oportunamente por sus lectores. La variedad y organización de contenidos hizo factible que ese banco de documentación de la cultura hispanoamericana sea consultado en sus diferentes contenidos. La visión de la investigadora Carvajal lo describe así:

El Repertorio Americano ofrecía una gama variada de artículos y comentarios; no se concentraba únicamente al mundo hispánico. Más bien, se podría caracterizar como una revista cosmopolita y humanista. En algunos números, se publicaron textos de Vladimir Lenin, Tolstoi, Gandhi, Augusto César Sandino, Miguel de Unamuno o de poetas latinoamericanos de tendencias vanguardistas, cuyas obras no encontraban cabida en otras publicaciones. Joaquín García, consideraba que el Repertorio era un transmisor de cultura, un instrumento educacional y ¿por qué no? un despertador de conciencias. Estas características permitieron que la revista ampliara su circulación, porque además de encontrar lectores en los países de habla hispana publicó algunos artículos en inglés, francés e italiano para cautivar esos públicos. (Carvajal, 2007, p. 149)

$\mathrm{Su}$ carácter humanista es representativo de esta publicación. No es de extrañar que se perfilara como un instrumento para diseminar información preciada en nuestra lengua materna, pero lo que es más valioso, fue el constituirse como un instrumento para el aprendizaje en diversos idiomas. Así facilitó que sus lectores enriquecieran su pensamiento crítico.

Por las características mencionadas, su sostenida publicación en cuanto a periodicidad y calidad, especialmente en el segundo período por Joaquín García Monge, demandó una gestión de red de editores, colaboradores (productores de contenidos), distribuidores y lectores. En este sentido, las redes constituyeron un elemento clave para su éxito, el cual no sólo consistió en su lectura, sino también en el impacto de proporcionar un fácil acceso a nueva información, proveniente de nuevo conocimiento para la sociedad hispanoamericana, en su desarrollo cultural, académico y social. Regresamos al pensamiento de Oliva:

Todo indica que una de las estrategias para mantener en pie Repertorio Americano y su vocación americanista está relacionada con una red de escritores e intelectuales los cuales ayudan a consagrar la 
Revista a través de sus opiniones: envían cartas, artículos y todo tipo de adhesiones con lo cual se fue consolidando el texto y fue creciendo la fidelidad al mismo. (Oliva, 2008, p. 35)

Como se mencionó, el Repertorio Americano ha tenido siempre como característica una red de colaboradores o de personas de disímiles disciplinas académicas que brindaron sus aportes para ser difundidos. En relación con su tercera etapa generada en la Universidad Nacional, Soto lo ve así:

La red intelectual que se gesta alrededor de la revista está compuesta de personas asociadas a las letras latinoamericanas, mayormente escritores, académicos e investigadores, especialistas en literatura, estudiosos de la filosofía y en los primeros números, también por geógrafos $\mathrm{y}$ biólogos. Un total de 229 autores costarricenses y latinoamericanos, en menor medida europeos, fueron publicados en ese período. Entre los escritores se identificaron colaboraciones de: Manlio Argueta, de El Salvador; Claribel Alegría, de El Salvador; Oscar Héctor Pralong y Luis Ricardo Furlan, de Argentina; Juan Garavito, de Colombia; Teresinka Pereira, de Brasil; David Gross, de Estados Unidos: Julián Gustems, de España; Mario Monteforte Toledo, de Guatemala; Arturo Uslar Pietri, de Venezuela, y los costarricenses: Quince Duncan; Carlos Rafael Duverrán, Lily Kruze, Leonor Garnier, Carlos Francisco Monge, Julieta Pinto, Alfredo Cardona
Peña, León Pacheco, Adela Ferreto, Carlos Luis Sáenz, Alfonso Chase, Carmen Naranjo y Laureano Albán, entre otros. (Soto, 2013, p. 170)

Es obligado destacar que esta publicación de carácter académico internacional de alta calidad ha facilitado un espacio para que nuevos pensadores jóvenes de diversas partes del mundo puedan compartir sus conocimientos. Esto también determina el gran impacto del Repertorio Americano en la sociedad hispanoamericana. Otro elemento relevante de esta institución es la amplia colección de números publicados a lo largo de sus diferentes etapas. Esta vasta colección de números publicados, como ya se comentó, llegó a consolidarse como un recurso de información de carácter histórico, social, económico, político y cultural hispanoamericano. Soto nos da la pauta en esta afirmación:

La revista, como documento histórico, permite rastrear, identificar y sistematizar experiencias. De tal forma, una revista académica encierra un universo en sí misma, donde los procesos de edición, impresión, circulación, lectores, políticas de publicación y distribución pueden dar cuenta de formas de producción y circulación del conocimiento, de los paradigmas políticos, educativos, científicos y culturales, de las formas de expresión y validación del canon científico que rigen no solo a la revista sino que conforman, y a la vez modelan, a la comunidad intelectual que da vida a la publicación. (Soto, 2013, p. 154) 
Si Repertorio Americano mantiene constante su producción de nuevos números se debe a que une en ella diversos intereses, como los de los escritores y el de los lectores en el medio. Así también, establece una relación de identificación "repertorioamericanista". Se da tanto, en primer lugar, entre el medio de publicación y el investigador, y en segundo lugar, entre el medio y el lector. Estos vínculos son fundamentales especialmente para los efectos de crear una motivación y persuasión en las mentes de estas personas para compartir su saber mediante la producción documental.

\section{Repertorio Americano como plataforma de gestión del conocimiento}

La gestión del conocimiento como es concebida en el siglo $\mathrm{XX}$, se originó por los aportes de una serie de especialistas en diversas disciplinas en esta área, quienes trabajaron en forma colaborativa e interdisciplinaria y marcaron diferentes tendencias. Esto hace posible el análisis del Repertorio Americano como una plataforma o medio que facilitó la gestión del conocimiento en su contexto histórico y cultural inmediato.

Para estos efectos, tomaremos las características y contexto de Repertorio Americano determinadas anteriormente. Las analizaremos a la luz de las actividades que las organizaciones realizan al implementar la gestión del conocimiento mencionadas por Thomas Davenport (1998).

\section{Generación de conocimiento}

El Repertorio Americano se constituyó en un facilitador de la gestión del conocimiento al activar, en primer lugar, la generación de conocimiento mediante la interacción social y liderar el proceso de conversión del conocimiento tácito en explícito, tomando como referencia la espiral del conocimiento del Nonaka y Takeuchi.

En este sentido, los colaboradores de contenidos para el Repertorio, tomaban su conocimiento tácito y lo transformaban en documentos escritos de diferente índole, los cuales eran publicados y así los transformaban en conocimiento explícito. Por lo tanto, los autores de estos documentos llevaron a cabo un proceso de identificación, selección, captura y organización de la información que luego la interiorizaron, socializaron y la combinaron para aplicarla y generar tanto su propio aprendizaje como conocimiento. Así pues, es importante resaltar como ejemplo de la situación mencionada la existencia de casos en el Repertorio en que varios autores en forma colaborativa publican un mismo documento, por lo que se hace evidente el esfuerzo de contribuir a la construcción de un cuerpo de conocimientos de forma multidisciplinaria.

Es así como el trabajo colaborativo y multidisciplinario tiene lugar mediante el establecimiento de relaciones interpersonales $y$, por ende, el establecimiento de redes de contactos o de intereses afines que facilitan tanto la generación como la gestión del conocimiento. En este sentido, el Repertorio Americano se gestiona con base en tres diferentes clases de redes que se encuentran vinculadas estrechamente a actividades concretas definidas por Thomas Davenport: en primer lugar, la gestión administrativa que va vinculada a la impresión, distribución y venta de la revista. 
En segundo lugar, la gestión de contenidos (correspondiente a la gestión de contactos y consecución de artículos por parte de docentes, investigadores $\mathrm{u}$ otros interesados en publicar) $\mathrm{y}$, tercer lugar, los lectores.

\section{Uso y acceso al conocimiento}

La red para la gestión administrativa del Repertorio fue de suma importancia, ya que presenta a los lectores o personas interesadas, una publicación de calidad (satisfacía tanto sus necesidades como sus expectativas). En el momento ideal se constituyó en un elemento clave para su posicionamiento y consumo. Esta publicación ofreció tanto un producto como un servicio de fácil acceso a la información impresa. $\mathrm{Su}$ procedencia fue de diversas partes de la región latinoamericana, persuadió a sus lectores a considerarla como una fuente de información referente para sus actividades y toma de decisiones. Esta dinámica se encuentra vinculada a las actividades de gestión del conocimiento indicadas por Davenport.

En lo referente al acceso del impreso de esta revista, es posible observar el surgimiento de agencias de distribución del $R e$ pertorio Americano en diferentes países, tanto de Centroamérica como de América Latina. Económicamente, especialmente en la segunda etapa, el Repertorio debía ser sostenible, lo cual fue un asunto difícil para Joaquín García Monge, como es posible apreciarlo en diferentes escritos. Por este motivo, y por la gestión de contenidos de la revista, es que García Monge se esfuerza tanto por coordinar la distribución y venta como su elaboración, para lo que fue indispensable la organización o sistematización de datos sobre escritores de diversas partes del mundo. El aporte Oliva permite esta afirmación:

Al finalizar la década de 1920, García Monge en varios números de la revista en la que se proporcionaban los nombres y direcciones de los escritores del Continente, cuya sección llamada "señas de escritores" lo cual es indicador de varias cosas que interesan. García Monge situaba en un altísimo interés el obtener los datos del mayor número de escritores de América, esto le valió varios adjetivos como, aquel que le gustaba tanto, "coordinador de América" acuñado por uno de los intelectuales más distinguidos, Alfonso Reyes. Este interés posiblemente estuvo en relación con su actividad como editor y con el carácter continental de la revista. De modo regular necesitaba de esta red de contacto en diversos países para conseguir artículos, que pudieran incluirse en cada una de las ediciones, conocer el desenvolvimiento cultural, literario y político; era frecuente encontrar polémicas, denuncias, que le enviaban estos contactos que a la postre se convertían en colaboradores. La publicación de dichas señas podía actuar como circuitos comunicantes entre los diversos escritores, algunos de ellos con residencias volátiles. La lista incluía escritores de América y España. (Oliva, 2008, p. 35)

Como es posible observar, el Repertorio llegó a consolidarse como un medio 
tanto para la difusión del conocimiento, así como también para que sus lectores pudieran mantenerse actualizados en lo referente a una amplia gama de temas.

\section{Crecimiento del conocimiento}

En relación con el crecimiento del conocimiento, con base en la cita anterior, este se vincula con la segunda red que es la de gestión de contenidos del Repertorio Americano. Podemos observar, con base en diferentes análisis de contenidos de esta revista, que esta se caracteriza por haber conformado una amplia colección de números, en un período de treinta y nueve años, con una temática amplia y humanista, conformada por diversos tipos de documentos o escritos (procedentes de una gran diversidad de lugares) tales como: poesía, artículos de diversa naturaleza, polémicas, denuncias y críticas. He ahí la razón por la que, con el transcurrir del tiempo, logró su reconocimiento y posicionamiento como fuente de información, caracterizándose especialmente por su crítica de la realidad social, cultural y académica de la región latinoamericana. Es importante resaltar el trabajo de Joaquín García Monge en el que constantemente recopiló y organizó la información de personas interesadas en difundir su pensamiento mediante un medio escrito. De esta forma, gestionó una red de contactos, como en la actualidad conocemos, y mediante una relación con ellos logró obtener importantes aportes que en la actualidad podemos leer en los números del Repertorio. En un inicio, no había personas interesadas, pero conforme pasó el tiempo fue creciendo esta red de colaboradores de contenidos y su gestión, hasta tal punto que debían esperar para ser publicados su escrito.
En la actualidad, gracias a estos grandes esfuerzos colaborativos es posible estudiar un recurso de información que registra en forma impresa la historia, la cultura, la política, la economía de Latinoamérica y que nos brinda la posibilidad de considerarla en el presente.

\section{Transferencia y asignación de valor al conocimiento}

La tercera red corresponde a la de los lectores del Repertorio y se vincula a la transferencia y asignación de valor al conocimiento. Maynez y Noriega hacen referencia al concepto de transferencia de conocimiento definido por Champika Liyanage y otros (2009) de la siguiente forma:

La transferencia de conocimiento es un proceso complejo que consiste en identificar, adquirir y aplicar el conocimiento existente (Liyanage et al., 2009). en dicho proceso, el emisor transmite su conocimiento, buscando que el receptor lo adquiera y aplique en sus actividades (Argote e Ingram, 2000; Liyanage et al., 2009), incluso de forma diferente de la del emisor. (Maynez y Noriega, 2015, p. 32)

La actividad de transferencia de conocimiento del Repertorio Americano se caracterizó por que tanto los autores de los documentos publicados como sus lectores formaron parte de este proceso.

En el caso de los lectores, identificaron $\mathrm{y}$ adquirieron el conocimiento difundido por esta publicación mediante su lectura. El interés que ellos mantienen para 
comprar el siguiente número, testifica que la lectura realizada potencia una aplicación a su realidad.

Con respecto a los generadores de contenidos como otro elemento del proceso de transferencia del conocimiento, es factible indicar que debieron realizar el proceso de identificación, adquisición y aplicación del conocimiento para luego transferirlo por la revista. En estas actividades se encuentra implícita la transformación de su conocimiento tácito en explícito, mediante la espiral del conocimiento, logrando así un aprendizaje que transfieren por medio del Repertorio a un público general.

\section{Registro y acceso al conocimiento digital}

Con respecto tanto a las actividades de gestión del conocimiento como de su registro y acceso, la revista que nos ocupa alcanza la etapa electrónica al vincularse con la Facultad de Filosofía y Letras de la Universidad Nacional. Se anexa entonces a la gestión por medio de los procesos técnicos bibliotecológicos y de las tecnologías web conocida como Biblioteca Electrónica Scriptorium.

Esta biblioteca es definida y caracterizada de la siguiente forma: "La biblioteca electrónica Scriptorium es un proyecto que difunde el trabajo académico de la Facultad de Filosofía y Letras de la Universidad Nacional mediante un conjunto de sitios virtuales integrados". (Universidad Nacional, Facultad de Filosofía y Letras, 2016, p. 1)

El Repertorio Americano al pasar a formar parte de los recursos de información de la Universidad Nacional y que su publicación haya sido asimilada al Instituto de Estudios Latinoamericanos, representa un baluarte de conocimiento de esta Facultad que debe ser gestionado en forma digital, para lograr una mayor difusión y acceso sin barreras o impedimentos. Por este motivo, siendo Scriptorium la biblioteca electrónica de esta, tiene una misión humanista acorde con la del Repertorio como lo vemos seguidamente:

La meta de Scriptorium es la recopilación, la sistematización, la digitalización y la divulgación de las publicaciones de las cinco unidades académicas de la FFL: Filosofía, Literatura y Ciencias del Lenguaje, Estudios latinoamericanos, Ciencias de la Religión, Estudios de la Mujer, Bibliotecología, Documentación e Información. El proyecto empezó a gestarse en 2005 con una pequeña colección bibliográfica; la segunda etapa dio inicio en agosto de 2010. Está a cargo de un equipo interdisciplinario que une la filología, la bibliotecología y la informática. (Universidad Nacional, Facultad de Filosofía y Letras, 2016, p. 1)

Así, no es de extrañar que esta biblioteca electrónica para el cumplimiento de su misión, considerara el inicio de la digitalización de esta publicación. Realizó los procesos técnicos de esta información por medio de las diversas herramientas tecnológicas seleccionadas. Así se busca que fuera posible su libre acceso, consulta, manipulación y difusión en las formas y medios actuales. 
Es importante resaltar que Scriptorium gestiona el conocimiento empleando una estrategia que incorpora elementos de promoción o difusión de los recursos de información. Se pretende así llegar a las diferentes clases de lectores o usuarios. Se complementa también con una gestión técnica que hace posible su localización, recuperación y acceso al texto completo. Se logra por medio de diferentes buscadores, redes sociales y herramientas web.

La mencionada estrategia de la Biblioteca ha sido llevada a cabo por medio de un repositorio de documentos, en donde se sistematizan y se promociona el acceso a publicaciones y documentos de la Facultad de Filosofía y Letras.

Es relevante destacar que Scriptorium cumple su misión con el mismo espíritu humanista de formación integral y armónica al igual que lo hizo el Repertorio Americano. Facilita, así, el acceso a la información de forma abierta o libre, sin restricción alguna. Por esta razón, es posible afirmar que esta biblioteca electrónica en la actualidad se encuentra vinculada a la corriente de acceso abierto a la información. Esto de acuerdo con lo definido por la Federación Internacional de Instituciones Bibliotecarias:

Acceso abierto es el nombre que actualmente se le da a un concepto, a un movimiento y a un modelo de organización cuyo objetivo es proporcionar libre acceso y re-uso del conocimiento científico presentado en forma de artículos de investigación, monografías, datos $\mathrm{y}$ otros materiales relacionados. El acceso abierto cambia los modelos prevalecientes actualmente en las publicaciones impresas, del pago por suscripción a un modelo de financiamiento que no cobra a los lectores o a las instituciones por el acceso a éstas. (Federación Internacional de Instituciones Bibliotecarias, 2010, p.1)

El acceso abierto a la información constituyó una política importante para la creación del repositorio, en el que se encuentra adscrito el proyecto de digitalización del $R e$ pertorio Americano. Con esta herramienta, es posible acceder, manipular y compartir con otras personas el valioso recurso de información, favoreciendo aún más las iniciativas de transferencia del conocimiento. Este se encuentra dentro del repositorio general de la UNA en la dirección http:// www.repositorio.una.ac.cr/scriptorium. La herramienta funciona con la plantilla DSpace y ofrece el acceso directo a las publicaciones académicas a texto completo.

También, en forma complementaria, estos 1.576 documentos del repositorio pueden ser consultados y accedidos por medio del catálogo electrónico del Sistema de Bibliotecas de la Universidad Nacional (SIDUNA): www.opac.una.ac.cr

Además de promocionar o difundir las publicaciones y su acceso a texto completo, la Biblioteca Scriptorium ofrece su portal www.scriptorium.una.ac.cr construido sobre la plataforma de Joomla. En este se albergan exposiciones virtuales, catálogos, información sobre el Certamen 
UNA-palabra, revistas de la Facultad de Filosofía y Letras e información variada de interés académico, así como una página dedicada a la práctica de la literatura.

Para los efectos de promocionar el acceso y conocimiento de la existencia en forma digital y en línea de los recursos de información en Scriptorium, se gestiona una página en redes sociales, concretamente en Facebook: www.facebook.com/scriptorium Esta herramienta se emplea principalmente para publicar anuncios sobre las publicaciones recientes de los otros sitios, recomendando lecturas de otras fuentes en línea, como sitios académicos, además de tener un contacto más directo con las personas interesadas en los diferentes recursos de información ofrecidos, así como por el Repertorio Americano.

La Biblioteca Electrónica Scriptorium, con base en su misión, establece una estrategia que lleva implícitos el concepto y metodología de la gestión del conocimiento. Establece una serie de recursos accesibles a sus integrantes en los diferentes procesos de generación de conocimiento, transformándolo de tácito en explícito, según lo acotado por Nonaka y Taekuchi con la espiral del conocimiento. Por este motivo, Scriptorium construye toda una red de colaboradores que gestionan contenidos de los diferentes recursos de información desde la propia Facultad de Filosofía y Letras. Cualquier persona interesada puede acceder a esta por medio de las tecnologías web. Constituye, así, el vehículo por medio del cual Repertorio Americano brinda su aporte a través de los medios tecnológicos. Es todo un pasado que se proyecta e impacta el presente.

\section{Conclusión}

El Repertorio Americano se ha constituido como un recurso de información humanista que es un baluarte de conocimiento de la región latinoamericana y española. Al mismo tiempo, conforma una plataforma que gestiona conocimiento por medio de las tecnologías.

Esta revista dejó un legado debido a que tanto por sus características propias, como por la gestión emprendida por sus editores, hizo posible una generación, sistematización, registro y difusión de información de tanta amplitud temática que en la actualidad es objeto de estudio. Es por esta razón, que el presente documento constituye un aporte general sobre la gestión del conocimiento en el Repertorio Americano y sugiere problemas para futuras investigaciones.

\section{Bibliografía}

Aja Quiroga, L. (2002). Gestión de información, gestión del conocimiento y gestión de la calidad en las organizaciones. Recuperado de: http:// eprints.rclis.org/5135/1/gestion.pdf

Area, M. y Guarro, A. (2014). La alfabetización informacional y digital: fundamentos pedagógicos para la enseñanza y el aprendizaje competente. Recuperado de: http://redc. revistas.csic.es/index.php/redc/ article/view/744/825

Boshyk, Y. (2016). Business Driven Action Learning: Global Best Practices. Recuperado de: https://books. google.co.cr/books?id=B851CwAA QBAJ\&pg=PA251\&lpg=PA251\& 
$\mathrm{dq}=$ matthia $\quad$ s+bellmann+academic \&source $=$ bl\&ots $=$ K0tGDOiDZ0 \& sig=zg- WA9BoD4ODw6ZXD2_ LKOTdUec\&hl=es\&sa=X\&redir esc $=\mathrm{y} \# \mathrm{v}=$ onepage $\& \mathrm{q}=$ matthias $\% 20 \mathrm{~b}$ ellmann\%20academic\& $\mathrm{f}=$ false

Carvajal Mena, L. (2007).El Repertorio Americano: Puente de Comunicación y Cultura. Recuperado de: https://dialnet.unirioja.es/descarga/ articulo/5556351.pdf

Davenport, T., Prusak, L. (1998). Working Knowledge: How organizations manage what they know. Boston, USA: Harvard Business School Press.

Federación Internacional de Instituciones Bibliotecarias (2010). Declaración de la IFLA sobre el acceso abierto - definición de su posición y política. Recuperado de: http://www. ifla.org/files/assets/hq/news/documents/ifla-statement-on-open-access-es.pdf

Máynez Guaderrama, A. I. y Noriega Morales, S. A. (2015). Transferencia de conocimiento dentro de la empresa: Beneficios y riesgos individuales percibidos. Recuperado de: http://web.a.ebscohost.com. una.idm.oclc.org/ehost/pdfviewer/ pdfviewer?sid=9df37a8e- a8b749dd-b64f-fa4eb92b3f8a\%40sessio nmgr4006\&vid $=2 \&$ hid $=4206$

Maynez, A. y Noriega, S. Transferencia de conocimiento dentro de la empresa: Beneficios y riesgos individuales percibidos. Recuperado de: http://www.redalyc.org/articulo. oa? $\mathrm{id}=13640682002$

Merton, R. (1964). Teoría y Estructuras Sociales. México: Fondo de Cultura Económica.
Mineralogical Record Inc. (2016). Gene Meieran. Recuperado de: http://www.minrec.org/labels . asp?colid $=1215$

Miranda, R. y Rodríguez, M. (2014). Diagnóstico de los recursos de información en el Tribunal Supremo de Elecciones por medio de la aplicación de una auditoría de información. Trabajo final de graduación para optar por el grado de Licenciatura en Bibliotecología y Documentación. Universidad Nacional. Heredia, Costa Rica.

Montero Segura, D. (1994). Las proyecciones históricas del Krausismo Español en Costa Rica (1870-1936). Trabajo final de graduación para optar por el grado de Doctorado en Historia del Pensamiento. Universidad Complutense. Madrid, España.

Montero Segura, D. (2006). Un acercamiento al curso de Historia de la Cultura desde una perspectiva humanista. San José, Costa Rica: Editorial de la Universidad de Costa Rica.

Montero Segura, D. (2006). El ensayo "La cultura Integral del Hombre" de Roberto Brenes Mesén. San José, Costa Rica: Editorial Costa Rica.

Oliva Medina, M. (2008). Historia de Repertorio Americano (1919-1958). Recuperado de: http://revistas. tec.ac.cr/index.php/comunicacion/ article/viewFile/987/894

Rodríguez, E. (1979). El pensamiento liberal. San José, Costa Rica: Editorial Costa Rica.

Soto Ramírez, M. (2013). El Repertorio Americano (1974-1983): Primera Revista Académica Fundada en 
la Universidad Nacional de Costa Rica. Recuperado de: http://www. scielo.org.co/scielo.php?script=sci arttext\&pid $=S 01227238201300010$ 0008\&l ng=en\&tlng=es.

Sveiby Knowledge Associates (2009). About Karl-Erik Sveiby. Recuperado de: http://www.sveiby.com/about_us.html Universidad Nacional. Facultad de Filosofía y Letras (2016). Scriptorium. Quiénes Somos. Recuperado de: http:// www.scriptorium.una.ac.cr/index. php/81-informacion/75-scriptorium
Universidad Nacional. Instituto de Estudios Latinoamericanos (2016). Repertorio Americano. Recuperado de: http://www.revistas.una.ac.cr/ index.php/repertorio/index

University of Toronto (2016). Robert K. Logan. Recuperado de: http:// www.physics.utoronto.ca/people/ homepages/logan/

Valhondo, D. (2013). Gestión del Conocimiento: del mito a la realidad. Madrid, España: Diaz de Santos. 